\title{
Viajes comerciales de intercambio en el departamento de Antofagasta de la Sierra, Puna meridional argentina: pasado y presente.
}

\author{
Silvia P. García ${ }^{1} *$ \\ Diana Rolandi* \\ Mariana López \\ Paula Valeri
}

Instituto Nacional de Antropología - Buenos Aires- Argentina

\begin{abstract}
Los viajes hacia valles interserranos a lomo de mula fueron una experiencia compartida por todos en esta región de la puna argentina, hasta hace veinte años. En este trabajo se relacionan los datos obtenidos a través de entrevistas a informantes en el departame nto de Antofagasta de la Sierra, con los surgidos tras la consulta de las Actas del Registro Civil y se arriba a conclusiones respecto de los vínculos de parentesco que unieron a quienes comerciaban e intercambiaban mercaderías producidas en alturas diferentes. También se compara la situación de entonces con la actualidad. En la capital del departamento los viajes de intercambio han desaparecido casi en su totalidad, en cambio en otras poblaciones del mismo departamento se han modificado incluyendo en ellos a las mercaderías obtenidas por compra y utilizando la sal como principal elemento de canje.
\end{abstract}

\section{Presentación}

Nuestro trabajo quiere describir la organización y finalidad del comercio realizado hasta hace pocos años a lomo de animal, hoy en día restringido a los poblados más aislados, y su relación con el establecimiento de vínculos sociales y de parentesco entre poblaciones de altura de la Puna argentina y las de los valles interserranos.

Para ello nos valdremos de los datos obtenidos principalmente en la Villa de Antofagasta de la Sierra y en la aldea de El Peñón por medio de entrevistas informales a 30 pobladores en viajes de campo realizados entre 1995 y 2001, y de la información lograda tras la consulta de las Actas del Registro Civil a partir de 1902.

\section{El área donde se realizó la investigación}

Aspecto físico

Antofagasta de la Sierra es un departamento que se encuentra ubicado al norte de la

1* SILVIAGR@ bibapl.edu.ar

http://revista-redes.rediris.es 
provincia de Catamarca, cuya capital es San Fernando del Valle de Catamarca distante $590 \mathrm{~km}$. de Antofagasta de la Sierra. El departamento limita al Norte y al Este con la provincia de Salta y al Oeste con Chile.

Su ambiente es lo que se denomina desierto de altura y está ubicado en el sector meridional de la puna andina. La altura sobre el nivel del mar en la que se encuentra todo el departamento oscila entre los 3200 y los 4400 metros. El clima es árido, con precipitaciones de régimen estival, de diciembre- marzo, siendo los valores promedio anuales inferiores a $100 \mathrm{~mm}$. La temperatura media anual es de 9,5 C y existe una gran amplitud térmica diurna y estacional.

Se pueden distinguir tres sectores ambientales: 1) fondo de cuenca, entre 3400 y 3550 m. s. n. m., con sectores de vega, tolar y campo. Es en este ámbito, que cuenta con agua permanente, madera para leña y cubierta vegetal para pastoreo, donde se concentra la mayor densidad de población; 2) sectores intermedios, entre 3550 y 3800 m. s. n. m., con una vegetación de tola y vegas, zona importante de tierras aptas para la agricultura y el forraje; 3) alta puna, entre los 3800 y los 4600 m. s. n. m. con escasa cobertura vegetal, y con pastura sólo para camélidos: llama y vicuña.

El departamento tiene una superficie de $28.098 \mathrm{~km}^{2}$ y está escasamente poblado: 923 personas (según el Censo Nacional de Población y Vivienda 1991 y cerca de 1400 según datos provisorios del Censo 2001), lo que significa una densidad de la población de 0,03 habitantes por $\mathrm{km}^{2}$, siendo prácticamente mitad varones y mitad mujeres. Las tierras del Departamento son fiscales. Por ocupación de muchos años se han obtenido títulos y éstos o el derecho a ocupación, se transmiten en herencia a los hijos.

\section{Caracterización sociocultural}

Tradicionalmente los pobladores de Antofagasta han sido criadores de ovejas y llamas y comerciantes de burros, vacas, ovejas y coca. La caza de chinchillas y vicuñas fue muy importante tanto en épocas prehispánicas como en épocas coloniales y durante el s. XIX y principios del s. XX (ver Holmberg, entre otros). La caza desmedida estuvo cerca de provocar la extinción de esta fauna. Desde hace unos cuantos años la vicuña es una especie protegida y su caza y comercialización están prohibidas. Por esta razón su 
importancia en la dieta o en la economía es prácticamente nula. El pastoreo en cambio siguió y sigue siendo definitorio respecto de muchos aspectos de la cultura.

Las mujeres se dedicaban principalmente a la cría del ganado y a la artesanía del tejido mientras los hombres eran los encargados de conseguir el dinero y los elementos necesarios para la supervivencia, que no se podían obtener en esas alturas desiertas. Para lograr esto, el trabajo en minas y canteras y la organización y realización de viajes a zonas bajas más fértiles fueron sus actividades primordiales. Los niños de ambos sexos ayudaban en sus primeros años en el cuidado del ganado, pero al crecer las mujeres colaboraban más con sus madres y los varones acompañaban a los hombres mayores en las caravanas y realizaban los escasos trabajos de agricultura que se podían llevar a cabo a 3500 metros de altura.

Esta división sexual del trabajo traía como natural consecuencia una mayor permanencia de las mujeres en las zonas de Puna: ellas llevaban a cabo una cierta trashumancia estacional, de acuerdo a las necesidades del ganado. Aunque hubo y hay hombres que cuidaban ovejas y llamas y mujeres que hacían viajes, éstas son aún las dueñas del ganado y quienes deciden acerca de su utilización. En Antofagasta, los bienes paternos no se reparten por igual entre los hijos sobrevivientes. La mejor parte de la vega, la vivienda y/o una parte mayor del rebaño es destinado al "shulka" - hijo/a menor -, o el que hubiere cuidado a los padres en la vejez. Es un indicador importante respecto de la mayor dedicación femenina al ganado el que hay muchas más mujeres que hombres beneficiarias de esta diferencia. Las hijas mujeres permanecieron más cerca del hogar paterno/materno porque se dedicaban al pastoreo del ganado.

Los hombres, en cambio, estaban gran parte del año ausentes, porque trabajaban por dinero en la minería (o en otras actividades que los llevaran fuera del ámbito puneño) o porque estaban realizando viajes para intercambiar lo producido en la zona.

\section{Los viajes y el comercio}

Podemos hablar de dos categorías de viajes: una se mantuvo vigente hasta las primeras décadas del siglo XX, y la otra, continuó hasta hace pocos años desde Antofagasta y 
continúa hoy desde El Peñón. A la primera corresponden los viajes que podríamos llamar estrictamente comerciales. Sus destinos eran los vecinos países de Bolivia y Chile y el objetivo fue llevar animales para vender y traer hoja de coca o dinero. Estos eran viajes largos, de uno o dos meses de duración.

A Chile se llevó ganado vacuno y lanar necesario, durante el siglo XIX, para alimentar a los habitantes de los pueblos y centros mineros en pleno auge entonces. Comerciantes chilenos venían a comprar ganado y contrataban arrieros para que los llevaran.

Los viajes a Bolivia terminaban en la lejana feria de Huari donde se intercambiaban burros por dinero: "plata blanca" o "boliviana", o por coca. La coca se vendía en Antofagasta. A veces esta coca boliviana llegaba a Antofagasta con los viajeros que habían ido a Chile, pues era y es más fácil pasar la frontera con contrabando desde Chile que desde Bolivia.

Ninguno de los actuales pobladores que han sido nuestros informantes en este tema han realizado estas travesías. Los adultos de hoy recuerdan lo que padres y abuelos les han contado. En estos viajes no participó ninguna mujer.

“Mi viejo llegó a Huari con burros, 30 días de ida y 30 días vuelta. Traían coca y plata blanca. Llevaban 30 ó 40 burros y volvían con 10 ó 20. A veces llevaban 100 ó 200. También iban a Chile: Toconao, Calama, Peine. 6 ó 7 días. Llevaban corderos y a veces vacunos que se compraban en Villavil, Belén o Laguna Blanca" (A. F., 1996).

Estos viajes entonces, realizados a los dos países con los que Antofagasta ha tenido mayor relación, no comprometían la producción familiar, redituaban dinero y no alimentos, y fueron importantes en tanto se explotaron los minerales en el norte de Chile y en Bolivia, actividad para la cual fueron útiles los burros de carga.

La segunda categoría de viajes a la que nos referimos arriba sí ha sido parte de la experiencia de la mayoría de los actuales pobladores y son los realizados a los Valles Calchaquíes en la provincia limítrofe de Salta y a los Valles Serranos de dos departamentos de la provincia de Catamarca a la cual pertenece hoy Antofagasta: los de Tinogasta y Belén. 
La Villa de Antofagasta se encuentra a $3500 \mathrm{~m}$. de altura, la aldea de El Peñón a $3580 \mathrm{~m}$. y tanto los Valles Calchaquíes como las zonas de Belén y Tinogasta, a las que llegaban más frecuentemente, se encuentran entre los 1400 y los 2200 metros. Desde El Peñón, todavía hoy en día se realizan viajes a puestos y estancias ubicados a gran altura, aunque solamente a aquellos donde no llega una ruta de vehículos.

Los hombres realizaban estos viajes para intercambiar lo producido por la unidad doméstica durante algunos meses, o durante el año - tarea que también realizaron algunas intrépidas mujeres -, o como "fleteros" o peones de acopiadores locales que les pagaban poco más que la comida. En estos casos las caravanas de burros eran más numerosas y llevaban predominantemente lana y tejidos. Los antofagasteños no recuerdan haber realizado estas travesías con llamas cargadas.

Los viajes se efectuaban dos o tres veces al año y, según la estación, se prefería uno u otro destino.

Todos viajaban en Cuaresma o Semana Santa hacia los valles Calchaquíes de Salta o a la zona de Fiambalá (Tinogasta) para traer fruta y verdura frescas y pasas de uva o de higo que fueron, junto con el fruto de la algarroba, la golosina de los niños de Antofagasta.

Otra caravana se organizaba después de la esquila o "cosecha" de lana en noviembre preferentemente al Departamento de Belén, en el cual había más demanda de lana y se pagaba a mejor precio.

Si era necesario y había algo que vender o trocar se llevaba a cabo un nuevo viaje en pleno invierno. Este era el peor, el más largo y sufrido. Se oyen aún casos de pobladores sorprendidos por tormentas de viento blanco, muertes de hacienda y arrieros por las heladas y amputaciones de miembros congelados:

"A V.F. se le heló toda la tropa en Aguas Calientes... Esto es cerca de la Cordillera. Lo consideraron desaparecido, no lo veían a V.F. Pero la mula nunca pierde el tino. Hay que darle rienda y ella sigue por el camino. Al día siguiente llegó a Paicuqui. Se le helaron los pies... Al otro día fueron a ver y toda la tropa estaba helada. Quedó la "huesería". (J.G., 1997).

La producción familiar era lana, hilados, tejidos, sogas, hondas, peleros, pullos, chalona y 
charqui (o sea, carne conservada en sal) de llama u oveja, cueros, hierbas medicinales ${ }^{2}$, alumbre ${ }^{3}$, "coipa" ${ }^{4}$, carne fresca y sal. Esta última se obtenía al atravesar algunas de las salinas que se encuentran en el camino hacia cualquiera de los tres destinos mencionados arriba.

Se intercambiaban estos productos por frutas y verduras frescas o secas, harinas o granos de maíz y trigo sin moler. Trocaban sus hierbas puneñas por las de los valles y trataban de adquirir todo lo que no podían obtener en la altura.

El trueque se realizaba a veces por medida: "almo por almo" (almud por almud): uno de sal por uno de maíz, o bien costal por costal: se vaciaba uno de lana y se lo llenaba con maíz. Según uno de nuestros informantes una maleta tejida o un pullo (manta tejida) se cambiaba por lo que podían cargar dos animales de granos o harina criolla (50 a $70 \mathrm{~kg}$. cada animal). Algunas veces se pesaba la carne y se cambiaba por la misma cantidad de kilos de grano o harina. Otras, se vendía algo y con ese dinero se compraba otra cosa: alimentos, enseres, ropa. El trueque era lo que primaba y hasta los animales de tiro y silla se conseguían asín .

Los viajeros se dirigían a lugares conocidos y trasmitidos de unos a otros. Se repiten los nombres de dueños de almacenes o comerciantes que podían alojar a los caravaneros en sus dependencias. A veces les cobraban el pastaje de los animales y otras no. Nunca les cobraron por dormir en esas dependencias. Si alguna vez subían a Antofagasta sus huéspedes los atendían también gratuitamente. En ocasiones al bajar dejaban los productos y al subir se recogían las mercaderías trocadas. Nadie viajaba sólo. Al menos dos adultos - muchas veces hermanos o padre e hijo -, y a veces varios más, unían esfuerzos y producción familiar.

Los burros quedaban en las afueras de los pueblos y los arrieros, salvo excepciones, no

\footnotetext{
${ }^{2}$ Cipolletti consigna formas de trueque de las hierbas medicinales en el caso de la puna jujeña (1984:516-17)

${ }^{3}$ El alumbre se usó desde antiguo como mordiente para teñir la lana. Se comerció, al menos desde el S. XIX a Belén, Tinogasta y Valles Calchaquíes. (Reichert, 1907:80-81).

4 La "coipa" es un carbonato de soda. Compuesto de carbonatos neutros y cloruro y sulfato de sodio ( ver Reichert, op. cit.:64). Se usó y se usa para lavar y para cocinar; por ejemplo, para hacer mazamorra (postre de maíz partido).

${ }_{5}$ D. Browman considera que, en los Andes, las tasas de intercambio estables (volumen igual por volumen igual o peso igual por peso igual) que pueden comprobarse desde el siglo XVI, son uno de los mecanismos para lograr el equilibrio en las transacciones. (Browman, 1994:27 y ss).
} 
entraban a ciudades importantes: trocaban o vendían antes de llegar a ellas. Fue en cierta forma un comercio "privado", nunca se establecieron en ferias o en plazas, llevaban su carga a almacenes o casas conocidas y allí intercambiaban.

Además de la carga para vender se llevaba lo necesario para comer esos días. Era comida sencilla: lo requerido para hacer una sopa, algo de carne, té o café.

Los niños servían para "atajar" a los burros que, en algunas bajadas, podían desbarrancarse. Por lo tanto, ellos hacían buena parte del camino a pie. Algunos mayores hacían lo mismo (D. R.,1996, E.C.,1997). En los destinos finales se comerciaba lo más rápido posible y se volvía. No había tiempo para ocuparse en otra labor que no estuviera vinculada al intercambio comercial ni se participaba en ningún tipo de celebración.

En el caso de otras zonas altas (como Perú) era común que los fleteros se emplearan en tareas diversas en los valles más bajos, tanto alquilando sus llamas en tareas de los agricultores, como trabajando ellos mismos en las cosechas. Solamente uno de nuestros informantes trabajaba en los valles cuando necesitaba dinero para sobrevivir, pero se trata de un poblador que se dedicó en forma exclusiva al comercio ambulante (C.M., 1998).

En las cumbres de toda ruta había una "apacheta" en la que todos sin excepción ofrecían algo a la Pachamama: coca, alcohol, o una piedra, y pedían tener un buen viaje, llegar al final de la travesía o, en las expresivas palabras de una informante: "que se acorten los caminos" (E. C., 1996).

\section{Los viajes y el parentesco}

La información que hasta aquí hemos volcado, ha sido obtenida en forma predominante a través de entrevistas con los actuales pobladores.

Al cruzar estos datos con los que hemos conocido consultando las Actas de Matrimonio, Nacimiento y Defunción del Registro Civil desde 1902, y con la información recabada al confeccionar árboles genealógicos, nos ha resultado muy interesante comprobar la tan conocida hipótesis de una relación que excede lo meramente comercial (Ver, entre otros, 
Inamura 1986, Flores Ochoa 1980 y Burchard 1980).

Los viajes de los que hemos hablado y que insumían entre 4 y 5 días para bajar, 4 días para las transacciones comerciales, y otros 4 ó 5 días para subir, requerían de paradas en sitios donde hubiera agua para hombres y animales. Allí descansaban burros y arrieros después de que los hombres aliviaban de sus cargas a las bestias.

“En las paradas conversábamos sobre otros viajeros, de los vientos, la nieve... con quién había viajado el viaje anterior a Angastaco, con quién se habían encontrado..." (J.M.D., 1996)

Estos sitios eran más o menos los mismos para todos. En algunas vegas había habitantes con los cuales tenían una relación en parte comercial, en parte familiar, según lo atestiguan a veces nuestros informantes y a veces el Registro Civil.

Si tomamos como ejemplo solamente las localidades que aparecen mencionadas en las Actas de Matrimonio como lugar de nacimiento o domicilio de los contrayentes o sus padres, hay más de 19 nombres que coinciden con sitios que eran destino final o paradas intermedias de las caravanas. Veamos algunos casos:

En 1903 se casan, en Antofagasta, Balvina Reales de El Peñón con Nicasio Ramos del mismo pueblo. La contrayente es hija de Maclovia Reales, domiciliada en CarachiPampa. El Peñón podía ser la primera jornada en el viaje a mula hacia el departamento de Belén, y Carachi- Pampa la primera jornada tanto desde El Peñón como desde Antofagasta para llegar al departamento de Tinogasta.

Isabel Quipildor, nacida en Molinos, es la madre de Francisco Morales nacido en La Sala, Fiambalá, quien en 1906 se casa en Antofagasta con Dominga Suárez nacida también en La Sala pero domiciliada en la Villa de Antofagasta. Como sabemos, Molinos, en los Valles Calchaquíes, fue destino de muchos viajes de los arrieros de Antofagasta y La Sala es una pequeña localidad del norte del Departamento Tinogasta en la que comerciaron muchos puneños.

Cuarenta o cincuenta años más tarde, siguen apareciendo estos vínculos:

En 1947 Tadeo Guzmán de Antofagasta de la Sierra se casa con María Muñoz nacida y 
domiciliada en Saujil, uno de los destinos preferido en los viajes hacia Tinogasta.

En 1956 Alfonsa Chaile nacida en Luracatao, hija de Tránsito Chaile nacido en Compuel, se casa con Atanasio Cerpa de Antofagasta de la Sierra. Luracatao hasta hoy en día es un destino importante dentro de los Valles Calchaquíes (Salta) y Compuel era la tercera o cuarta jornada en el camino a esos mismos valles. Por otro lado, Chaile es el apellido de comerciantes que compraban o cambiaban a los arrieros. (Ver Mapas al final del trabajo).

En los árboles genealógicos, en los que hemos registrado cerca de 200 nombres, además de comprobar el origen extra-puneño de parte de la población actual, volvemos a encontrarnos tanto con antepasados como con descendientes nacidos dentro del área de influencia de estos "caminos de herradura" (de cabalgaduras), especialmente del que llevaba hacia Tinogasta: A. R. nació en La Mesada, Tinogasta, de familia oriunda de El Peñón (Departamento Antofagasta) y allí tuvo hijos. Subió más tarde a Carachi- Pampa y finalmente en 1952 se casó son S.M. en Antofagasta de la Sierra, donde aún viven. El marido había nacido en La Ciénaga, Tinogasta, y residía en la Villa de Antofagasta de donde era oriunda la familia de su madre. Los hijos de la primera unión de A.R. viven en Medanitos, los otros en Antofagasta y en Belén.

$Y$ finalmente, los 30 informantes, a quienes entrevistamos respecto de este tema, lo confirman. El límite entre "conocido", "pariente" o "amigo" no es muy nítido. A veces, según la información de Registro Civil nosotros sabemos que son parientes algunos que no se consideran tales. Además, muchos de nuestros informantes dejaron de viajar en la adolescencia, viajaban aún con adultos y no saben precisar el grado de parentesco o amistad que los unía con los que comerciaban. Nuestra hipótesis es que en algunos casos los parentescos remotos dejaron de considerarse lazos de familia y se tuvieron por amigos o conocidos con quienes se siguió comerciando. En otros casos la relación de amistad y comercio previa favoreció la realización de un matrimonio que convirtió esa relación en familiar, como en el caso de los Chaile. ${ }^{6}$

\footnotetext{
${ }^{6}$ Aunque sería tema para otro trabajo quisiéramos consignar que en nuestra zona las uniones transitorias y los hijos productos de ellas, fueron aceptadas socialmente al menos desde mitad del siglo XIX. Las Actas de Nacimiento y las bautismales a partir de 1849 registran siempre un altísimo porcentaje de hijos naturales y, por lo tanto, un igualmente alto grado de transmisión del apellido materno. De todas maneras, los descendientes saben quiénes y de donde fueron sus progenitores varones. También en estos casos esta información nos remite a los valles de Tinogasta en primer lugar, de Belén y a los Calchaquíes de Salta en menor medida.
} 
Autores que han trabajado con sociedades de pastores en el Perú han subrayado la importancia que el compadrazgo adquiría en estas transacciones (por ejemplo Flores Ochoa, 1977 y Juvenal Casaverde, 1977). No es el caso de Antofagasta. Los implicados en el trueque podían ser parientes consanguíneos o políticos, amigos o conocidos pero nunca compadres. Los padrinos de los hijos se han buscado entre personas de prestigio: maestros, médicos, la gente más rica del pueblo, "vallistos" o habitantes de las ciudades como Salta o Catamarca, pero nunca fueron los mismos con los que los antofagasteños comerciaban en forma habitual. Si los implicados viven en el mismo pueblo la relación es de respeto, pero no hemos constatado ningún intercambio especial de favores o de bienes.

A través de lo dicho por los pobladores actuales y por lo consignado en las Actas de Matrimonio del Registro Civil podemos vislumbrar una red de conocidos, amigos y parientes - nunca compadres- que están ubicados en nudos claves de la red de trueque. 
Tabla 1: Desde Antofagasta. Destinos, Paradas, Tiempo empleado, Productos trocados, Relaciones sociales. en el pasado.

\begin{tabular}{|c|c|c|c|c|c|}
\hline $\begin{array}{l}\text { Destino del } \\
\text { viaje }\end{array}$ & Paradas & $\begin{array}{l}\text { Duración de } \\
\text { las Jornadas }\end{array}$ & Productos que llevaban & Productos que traían & Relaciones Sociales \\
\hline $\begin{array}{l}\text { Belén/ } \\
\text { Corral } \\
\text { Quemado }\end{array}$ & $\begin{array}{l}\text { 1. El Jote } \\
\text { 2. El Peñón/ Pasto Ventura } \\
\text { 3. Laguna Colorada/ Pozuelos } \\
\text { 4. Nacimientos de San Antonio } \\
\text { 5. Corral Colorado } \\
\text { 6. Villavil } \\
\text { 7 Corral Quemado } \\
\text { 8. San Fernando } \\
\text { 9. Puerta San J osé de Belén. } \\
\text { 10. Belén }\end{array}$ & $\begin{array}{l}\text { 1. } 12 \text { horas } \\
\text { 2. } 7 / 8 \text { horas } \\
\text { 3. Extracción } \\
\text { de sal } \\
\text { 6. } 6 \text { horas } \\
7.4 \text { horas }\end{array}$ & $\begin{array}{l}\text {-lana de oveja y/o llama } \\
\text { - cueros de oveja y cabra } \\
\text {-tejidos: peleros, pullos, } \\
\text { frazadas. } \\
\text {-charqui / chalona }\end{array}$ & $\begin{array}{l}\text {-azúcar. } \\
\text { - harina. } \\
\text { - cereales (maíz/ } \\
\text { trigo). } \\
\text { - vino. } \\
\text {-zapallo de angola. }\end{array}$ & $\begin{array}{l}\text { 5. Alojamiento: Lauro Chaile } \\
\text { 6. Alojamiento: Indalecio Pachado o } \\
\text { Solano Pachado } \\
\text { 7. Alojamiento: Aibar } \\
\text { 9. Alojamiento: Cornelio Quipildor. } \\
\text { 10. Se buscaba mercadería: en casa } \\
\text { de Vélez o Rojas }\end{array}$ \\
\hline $\begin{array}{l}\text { Palo Blanco/ } \\
\text { Fiambalá }\end{array}$ & $\begin{array}{l}\text { 1. Carachipampa } \\
\text { 2. Agua el Médano u Ojo de las } \\
\text { Cortaderas } \\
\text { 3. Chuquisaca } \\
\text { Diligencias a: } \\
\text { 4. La Mesada/ La Ciénaga/ Antinaco } \\
\text { Palo Blanco por Agua Negra } \\
\text { 5. Nacimientos / Medanitos } \\
\text { 6. Fiambalá }\end{array}$ & $\begin{array}{l}\text { 1. } 8 \text { horas } \\
\text { 4. } 1 / 2 \text { día de } \\
\text { camino }\end{array}$ & $\begin{array}{l}\text { - charqui de llama/cabra/ } \\
\text { cabra, chalona } \\
\text { - lana. } \\
\text { - cueros de cabra. } \\
\text {-tejidos: peleros, frazadas, } \\
\text { medias }\end{array}$ & $\begin{array}{l}\text {-peras, higos, duraz- } \\
\text { nos, manzanas, } \\
\text { sandías, zapallo. } \\
\text { - harina. } \\
\text { - algarroba. }\end{array}$ & $\begin{array}{l}\text { 3. Alojamiento: Adrián Chaile o Jesús } \\
\text { Ramos } \\
\text { 4. Alojamiento: Cornelio Reales o } \\
\text { Francisco Carrizo }\end{array}$ \\
\hline $\begin{array}{l}\text { A los Valles } \\
\text { desde } \\
\text { Nacimientos } \\
\text { o Trapiche }\end{array}$ & $\begin{array}{l}\text { 1. Cancha Argolla } \\
\text { 2. Aguas Calientes o Río Purulla } \\
\text { 3. Patos } \\
\text { 4. Barrancas } \\
\text { 5. Amaicha por Tacuil }\end{array}$ & $6 / 7$ horas & $\begin{array}{l}\text { - sal } \\
\text {-tejidos. } \\
\text { - coipa }\end{array}$ & $\begin{array}{l}\text { - trigo. } \\
\text { - maíz. } \\
\text {-fruta. } \\
\text { - algarroba. }\end{array}$ & 3. Alojamiento: Venancio Ramos \\
\hline $\begin{array}{l}\text { Molinos / } \\
\text { Quebrada } \\
\text { De Hualfín }\end{array}$ & $\begin{array}{l}\text { 1. Pirica. } \\
\text { 2. León Muerto (Cueva Ne gra, } \\
\text { Blanca o Grande) } \\
\text { 3. Atacamara/ Compuel } \\
\text { 4. Hualfín/ Amaicha (por Tacuil) } \\
\text { 5. Molinos }\end{array}$ & $\begin{array}{l}\text { 1. } 8 \text { horas } \\
\text { 2. } 12 \text { horas. } \\
\text { 3. } 12 \text { horas } \\
4.10 / 15 \\
\text { horas }\end{array}$ & $\begin{array}{l}\text { - Sal (se buscaba en } \\
\text { Laguna Diamante) o Salar } \\
\text { del Hombre Muerto. } \\
\text { - Tejidos/lana/sogas } \\
\text { - rica-rica y otros yuyos. } \\
\text { - carne/ coipa. }\end{array}$ & $\begin{array}{l}\text { - harina de trigo } \\
\text { - maíz. } \\
\text { - fruta } \\
\text { - chucherías. } \\
\text { - artículos comestibles. } \\
\text { - algarroba. }\end{array}$ & $\begin{array}{l}\text { 4. Alojamiento: Escalante o Liquín. } \\
\text { 5. Alojamiento: Ernesto Díaz. }\end{array}$ \\
\hline $\begin{array}{l}\text { A Pastos } \\
\text { Grandes / } \\
\text { San Antonio } \\
\text { de los } \\
\text { Cobres }\end{array}$ & $\begin{array}{l}\text { 1. Trapiche } \\
\text { 2. Horno de la Falda Ciénaga. } \\
\text { 3. Tolar Grande. } \\
\text { 4. Horno de Colorado } \\
\text { 5. Pastos Grandes. } \\
\text { 6. Abra El Gallo. } \\
\text { 7. San Antonio de los Cobres. }\end{array}$ & & -dinero & -mercadería & 5. Alojamiento: Santiago Delgado \\
\hline
\end{tabular}




\section{El presente del comercio}

En 1978 se abrió la ruta para vehículos que une esta parte del inmenso territorio puneño con la provincia a la cual pertenece políticamente desde 1943. Poco a poco: primero con camiones y camionetas, hace más de cinco años con un transporte colectivo que realiza el viaje una vez por semana, y con una pista de aterrizaje para aviones - medio por el cual se puede llegar a veces-, además de una antena repetidora de T. V. y una radio de frecuencia modulada, el aislamiento de la Villa de Antofagasta de la Sierra ha ido desapareciendo.

Esto naturalmente afectó por un lado a los medios y los caminos usados para comerciar y por otro lado, a las pautas de consumo, o sea, a qué se considera necesario.

Como la ruta para vehículos une Antofagasta con Belén y su área de influencia, zona a la que tradicionalmente se iba a lomo de mula a vender, estos vínculos se han reforzado y varias familias que siguen teniendo casa y hacienda en la Villa viven una parte del año en Belén y Catamarca o mandan a sus hijos a estudiar allí.

Los destinos tradicionales a Fiambalá en el departamento Tinogasta y a zonas intermedias hacia los Valles Calchaquíes, también han dejado de frecuentarse desde la Villa, aunque no desde otros poblados.

En cuanto al comercio en sí podríamos decir que ya no es tan necesario bajar para conseguir alimentos, enseres o ropa. En la Villa de Antofagasta hay varios almacenes que venden y compran y también depósitos de camioneros que, desde Salta, Catamarca, Tinogasta o Santa María llegan con los productos necesarios que, o bien se pagan con tejidos, especialmente con una pieza para el apero de montar denominada "pelero", con lana o hilados, o con dinero. Este dinero hoy proviene especialmente del empleo público que en Antofagasta se ha multiplicado desde el advenimiento de los Gobiernos democráticos en 1983, y que son parte de las transacciones de un clientelismo político particular. Considerados objetivamente estos sueldos son de poco monto, pero percibidos en forma regular les permite, quizás por primera vez, comprar a crédito.

En la Villa los pobladores autóctonos trabajan en la Municipalidad, como enfermeros y personal de limpieza en el Hospital, como cocineras y personal de limpieza del comedor 
escolar, del comedor infantil y de la Hostería Municipal, como artesanas (también en la Municipalidad), como agentes de la Policía de la Provincia, como obreros o empleados de la Comisión de Riego y de la Empresa de Electricidad y son obreros o empleados de las minas. Además hoy viven y gastan allí maestros, profesores y directores de las dos escuelas, agentes de la Gendarmería que se reemplazan cada 30 días, y también en forma temporaria, personal de todo tipo de las canteras y la exploración y explotación de minas (hoy de nuevo en plena actividad). Unos pocos argentinos y extranjeros han comenzado a llegar a la zona en visitas de "turismo de aventura" pero aún es difícil saber en que afectarían ellos a las pautas de consumo.

Los camiones traen fruta y también yogures, quesos, latas de gaseosas, jugos o cerveza. En los últimos años se han ido reemplazando las cocinas o "fuegueros" a leña por cocinas a gas, y los "estrados" de adobe por camas. Las mujeres y hombres usan blue-jeans, relojes, camperas de tela impermeable, zapatillas de marcas conocidas, escuchan cassettes, ven videos y hacen deportes. Para adquirir estos bienes, o bajan a las pequeñas ciudades en el transporte colectivo o compran a los camioneros, para quienes subir colchones, camas, garrafas y equipos de música es más sencillo.

A pesar de lo dicho el trueque no ha desaparecido $y$, exceptuando lo que se compra a crédito en Antofagasta, todo lo demás puede trocarse por lana o tejidos. A este cambio o trueque de un producto por otro lo llaman "cambalachear" ("cambalacheo la lana"). Además de los comerciantes más fuertes, llegan a Antofagasta y recorren otros poblados y "puestos" del departamento, pequeños comerciantes emparentados con los habitantes de la villa. Éstos, que no poseen vehículo propio, llegan en camiones o en el transporte colectivo con su mercadería y a veces, en bicicleta. Traen los más diversos productos pequeños y en poca escala: cremas, peines, hilos de coser, juguetes, pañuelos, cinturones. Aceptan como pago lana, hilo y peleros que comercian en los mismos destinos que los comerciantes grandes pero no acceden a los comercios céntricos sino a los barrios marginales. Podemos suponer que siempre vinieron, aunque los únicos que la gente recuerda como pequeños comerciantes de antaño son los bolivianos que vendían remedios naturales.

Todo lo descrito es válido para los habitantes de la Villa de Antofagasta, que es la que más se ha beneficiado de todas las localidades del mismo departamento con los caminos 
y los transportes actuales. El resto continúa en un grado variable de aislamiento que a veces es el mismo de principios del siglo XX. Este es el caso de poblaciones como El Peñón, Nacimientos, Antofalla y Las Quinoas y de los pobladores dispersos de los alrededores del Salar del Hombre Muerto. De estos últimos tenemos el testimonio de una joven de 21 años, quien viajó desde Huaichar hasta Luracatao en los Valles Calchaquíes Salteños hasta 1991. Desde allí llevaban sal, carne fresca y seca, hierbas medicinales, sogas y hondas hechas con lana y peleros. Para preparar la sal trabajaba toda la familia en el salar dos días. Sacaban la sal en panes grandes, y luego de limpiarla la cargaban en los burros. Un cambio posible era tres panes de sal por una carga de uva. Otras veces subían los "salineros" y a ellos se les trocaba tres peleros por un burro.

\section{El caso de El Peñón}

En lo que respecta a El Peñón, lejos están los viajes a lomo de mula de haber desaparecido. En esta población, ubicada a unos 80 kilómetros al sur de la Villa de Antofagasta, hemos podido constatar - a través de las entrevistas a sus pobladores en los años 2000 y 2001 - que el comercio de una amplia variedad de comestibles, entre los cuales es de gran importancia la sal, se hace mediante animales de carga. La imposibilidad de los camiones, debido a la ausencia de caminos, de llegar a zonas alejadas y aisladas de la puna ha permitido que el tipo de comercio tradicional perdure hasta nuestros días.

La preparación del viaje a lomo de mula no es para inexpertos, en general se trata de personas que saben del oficio porque sus padres les han enseñado desde chicos.

“Uno ya está acostumbrado a viajar desde chico, de el tiempo que yo viajé con mi papá" (D. S. 2000).

Por eso, a quien sabe cómo iniciarlo y se encuentra desocupado estacionalmente, se le presenta como una muy buena posibilidad laboral.

"Yo no tengo trabajo, no tengo nada y yo me tengo que buscar la vida a lomo de animal, a lomo de burro para dar de comer a mis hijos" (D. S. 2000). 
Contrastando con la importancia que la lana y los tejidos tuvieron en otros tiempos, hoy la mercancía más importante para iniciar un viaje de intercambio es la sal. La lana de oveja e incluso la de llama se han depreciado notablemente. Solamente después de hilada y tejida adquiere algo de valor. Aún así, hoy y desde El Peñón no pueden competir con el hilado y tejido de otras zonas. La sal, en cambio, sigue siendo un vital elemento y una mercadería rendidora. Los viajes así se inician con un bien que se obtiene gratuitamente. Lo único que se invierte para obtener la sal es el trabajo de no más de 2 días para cargar un promedio de 15 burros. Cada burro puede trasladar 50 kilogramos de sal en una bolsa, por lo tanto estos viajeros comienzan su viaje con un cargamento de entre 500 a 750 kilogramos de este elemento.

“...nada más (que sal). Lana no porque la lana no la compran, no vale. No vale el tejido, no vale la lana. ( $\mathrm{Ni}$ ) las ovejas... y no las puedo vender así que... antes no, antes valía todo, así que uno sacaba un poco "i lana y ya compraba las cosas" (D. S. 2000).

La sal es extraída del cercano salar de Pairique. Los arrieros que la extraen la colocan sobre el monte para exprimir un poco el agua, y luego sobre una grama (una vega con gramilla) para que termine de secarse. En un día pueden conseguir y secar hasta 15 bolsas. Después la llevan en grano y la ponen en bolsas de papas.

Al bajar, se cambia medida de volumen por medida de volumen, en general por uva o pasas de uva. En caso de "apreciarse" o sea en caso de ponerle un precio nominal al kg. de sal, este es de 50 centavos.

Cada bolsa puede ser cambiada por una cría de llama macho o hembra. También cambalachean - kilo a kilo - la sal por maíz, papa o cebolla, en la época en que hay esos cultivos.

La sal es usada para hacer el pan en las panaderías y para el consumo diario de las personas - que la consideran, a veces, menos "picante" que la comprada. A los animales (ovejas, vacas, caballos) se les da "porque es un remedio para darles a ellos." Algunos dicen que además, sirve para salar las aceitunas o hacer charqui. Otros la revenden.

La sal de Pairique llega a distintos puntos geográficos. Es llevada por el este hasta lugares de la provincia de Salta, hacia el sudoeste a Medanitos y Antinaco, a Belén en el 
sur y a la Ciénaga. Es cambiada por manzanas, pasas de higo y de uva, zapallo angola, maíz y otros, se dice que debe ser "apreciada por ambas partes", o sea, comprador y vendedor deben acordar su valor en relación a los otros productos.

Las uvas y pasas de uva al llegar a la puna se vuelven a trocar por otros productos por ejemplo carne fresca, animales vivos (llamas, ovejas o cabras) o lana. Aunque habitualmente la hacienda que los pobladores llevan a El Peñón se compra con dinero, pueden conseguirse también por trueque en buenas condiciones para los viajeros puesto que las frutas en la altura se han valorizado y ya se "aprecian" a 1,50. La carne que no se consume es entregada junto con la lana a una tejedora a cambio de piezas ya tejidas que inician otros circuitos de intercambio a través de los camiones o de los acopiadores de tejido.

También se "trajina" ropa, remedios, yuyos y "chucherías" para cambiar por papa, maíz, frutas, frutas secas, quesos.

En la gran mayoría de los casos - en lugares como Pampa Llana, Río Grande, Cardones, Laguna Blanca, La Ciénaga, Antinaco - los viajeros se alojan en la casa de algún amigo o conocido que les brinda cama sin cobrarles la estadía. Siempre debe ser un lugar con agua y pasto para los animales por el cual a veces, pagan. En otras ocasiones pasan la noche a campo abierto o resguardados en una pirca ${ }^{7}$. Sólo en Ojo de las Cortaderas y Manantiales parecen pagar por un alojamiento nocturno y uno de nuestros informantes tiene "un rancho" en el salar de Pairique, en el cual él y algún hijo que lo acompañe, pueden dormir.

Los viajeros están protegidos. En los caminos que recorren hay apachetas donde acostumbran hacer ofrendas a la Pacha. Allí dejan coca, alcohol, cigarrillos y harina cocida que llevan preparada. Durante la "corpachada" se le pide a la Pachamama que el viaje sea bueno y que de "tiempo" para hacer las diligencias porque hay que volver rápido y algunos meses, sobre todo agosto, son bravos. Una apacheta importante y concurrida por los comerciantes es la de Abra del Bayo, situada en el camino hacia Laguna Blanca, detrás de un cerro.

\footnotetext{
${ }^{7}$ Pared rústica hecha por lo general de piedras.

8 "Corpachar": ofrendar a la "Pachamama", la madre tierra.
} 
"Yo siempre le pido así (a la Pacha)... que me ayude, que ande bien, que haga buen negocio para lo qui llevo" (F. Q. 2001).

La frecuencia de los viajes es muy variable. De los consultados por nosotros, el de más edad (mayor de 60) sólo viaja una vez al año y hacia Fiambalá. Los jóvenes lo hacen más seguido (dos o tres veces) y uno de ellos todos los meses emprende la travesía pero solamente a los lugares más cercanos: Laguna Blanca y los puestos y estancias ubicados hacia la provincia de Salta son sus destinos.

Como vimos, la sociedad de consumo que se impone a través de los medios masivos a una sociedad en extremo austera como fue la puneña, y la posibilidad de trasladarse y trasladar productos a través de un camino para vehículos, no han logrado eliminar en forma definitiva al trueque como forma de intercambio. Las transformaciones, entre las cuales no es la menor la de poder conseguir dinero sin salir de las poblaciones a las que llegan camiones gracias a la ruta, han afectado en primer término a la capital del departamento.

En el caso analizado de El Peñón, aunque es obvio que estos viajes siguen estrechando vínculos antiguos y anudando nuevos, su incidencia en las relaciones de parentesco, todavía nos resulta incierta por carecer de suficientes datos. 

TABLA 2 : Viajes desde El Peñón en la actualidad

\begin{tabular}{|c|c|c|c|c|}
\hline Paradas & Duración de las J ornadas & Productos que llevan & \begin{tabular}{|l|} 
Productos que traen \\
\end{tabular} & Lugar donde se duermen \\
\hline $\begin{array}{l}\text { 1. Pairique } \\
\text { 2. La Cieneguita } \\
\text { 3. Aparoma } \\
\text { 4. Leislé } \\
\text { 5. Pampa Llana } \\
\text { 6. Río Grande } \\
\text { 7. Cardones }\end{array}$ & $\begin{array}{l}\text { 1. } 1 \text { día más } 3 \text { o } 4 \text { días en el lugar. } \\
\text { 2. } 8 \text { horas } \\
\text { 3. } 8 \text { horas } \\
\text { 4. } 6 \text { horas } \\
\text { 5. } 8 \text { horas } \\
\text { 6. } 1 \text { día } \\
\text { 7. } 1 \text { día, se queda } 3 \text { o } 4 \text { días }\end{array}$ & $\begin{array}{l}\text { - Sal } \\
\text { - Pasas de higo y de uva } \\
\text { traídas de Fiambalá. } \\
\text { - Ropa } \\
\text { - Rica rica } \\
\text { - } 18 \text { a } 20 \text { animales }\end{array}$ & $\begin{array}{l}\text { - Llamito } \\
\text { - Maíz } \\
\text { - papa } \\
\text { - Cebolla }\end{array}$ & $\begin{array}{l}\text { 1. Alojamiento } \\
\text { 2. En el campo, en una pirca. } \\
\text { 3. Pirquita. } \\
\text { 4. Campo } \\
\text { 5. Casa de un amigo } \\
\text { 6. Casa de un amigo } \\
\text { 7. Casa de un amigo }\end{array}$ \\
\hline $\begin{array}{l}\text { 1. Pairiqui } \\
\text { 2. Ojo de las cortaderas } \\
\text { 3. La Mesada } \\
\text { 4. Antinaco/ Palo Blanco/ } \\
\text { Medanitos }\end{array}$ & $\begin{array}{l}\text { 1. Se queda } 2 \text { días } \\
\text { 3. } 1 \text { día } \\
\text { 5. } 2 \text { días }\end{array}$ & \begin{tabular}{|l}
- Sal \\
-20 o 15 animalitos
\end{tabular} & \begin{tabular}{|l|}
-Pelones \\
- Orejones \\
-Zapallo angola \\
- Queso \\
- Nuez \\
- Manzanas \\
- Pasas de higo y de uva
\end{tabular} & $\begin{array}{l}\text { 2. Alojamiento, vega y pasto para los } \\
\text { animales }\end{array}$ \\
\hline $\begin{array}{l}\text { 1. Cavi } \\
\text { 2. Laguna Blanca } \\
\text { 3. Aparoma }\end{array}$ & & - Pasas de uva & -Llamas & $\begin{array}{l}\text { 2. Casa de los Escalante sólo conocidos, } \\
\text { no parientes }\end{array}$ \\
\hline $\begin{array}{l}\text { 1. Cavi } \\
\text { 2. Corral Blanco } \\
\text { 3. Laguna Blanca } \\
\text { 4. Aguas Calientes }\end{array}$ & $\begin{array}{l}\text { 1. } 13 \text { horas/ } 20 \mathrm{Km} \\
\text { 2. } 1 \text { día } \\
\text { 3. Se queda } 10 / 12 \text { días }\end{array}$ & $\begin{array}{l}\text {-Ropa } \\
\text {-Remedios (geniol) } \\
\text {-Animales muertos (pocos) }\end{array}$ & $\begin{array}{l}\text { - Hilos y Lanas } \\
\text {-Yuyos } \\
\text { - Hacienda (ovejas y } \\
\text { llamas) } \\
\end{array}$ & $\begin{array}{l}\text { 3. Casas de conocidos sin pagar } \\
\text { 4. Es un puesto }\end{array}$ \\
\hline $\begin{array}{l}\text { 1. Pairique } \\
\text { 2. Agua de Médano } \\
\text { 3. Quebrada de Chuquisaca } \\
\text { 4. El Delgadito } \\
\text { 5. La Ciénaga } \\
\text { 6. Antinaco }\end{array}$ & $\begin{array}{l}\text { 1.1/2 hora paró } 2 \text { días } \\
\text { 2. } 13 \text { horas } \\
\text { 4. } 8 \text { horas } \\
\text { 5. } 5 \text { horas } \\
\text { 6. } 4 \text { horas }\end{array}$ & $\begin{array}{l}\text {-Sal } \\
\text {-Yuyos: copa, espinillo, } \\
\text { pupusa, boldo } \\
\text {-Charqui y chalona (a } \\
\text { veces) }\end{array}$ & $\begin{array}{l}\text {-Pasas } \\
\text {-Uvas } \\
\text {-Zapallos angola } \\
\text { - Yuyos "de abajo" }\end{array}$ & $\begin{array}{l}\text { 4. Casa de Pedro Reales, delegado } \\
\text { municipalidad de la Ciénaga. No pagó. } \\
\text { 5. Casa de Don Sixto González } \\
\text { 6. Casa de Jesús Salgado, un amigo. }\end{array}$ \\
\hline $\begin{array}{l}\text { 1. Cavi } \\
\text { 2. Peñas Blancas } \\
\text { 3. Laguna blanca }\end{array}$ & & \begin{tabular}{|l|}
-Ropa \\
- “Chucherías” \\
-Remedios \\
\end{tabular} & $\begin{array}{l}\text { - Hacienda chica: ovejas, } \\
\text { cabras y llamas. }\end{array}$ & \\
\hline
\end{tabular}




\section{Conclusión}

Quisiéramos finalmente sintetizar lo que hasta ahora, a través de la información recogida en Antofagasta de la Sierra y de la consulta de las Actas del Registro Civil y Parroquial, podemos afirmar.

La actual población de la Villa parece conformar un gran árbol genealógico. Todos sus integrantes están emparentados entre sí. Al consultar el Registro Civil vemos que los extraños al grupo y relacionados a ellos por lazos de matrimonio, provienen de localidades vinculadas a los caminos de herraduras por los cuales los antofagasteños comerciaban. Los destinos de estos viajes han ido cambiando desde fines del s. XIX y hasta el final del s. XX. Los viajes a Chile y a Bolivia han desaparecido y consecuentemente, los parentescos que en el s. XIX parecen haber sido muy estrechos. Durante el siglo XX los viajes fueron acentuando su carácter familiar y los destinos fueron los valles fértiles de la República Argentina. A estos valles y a las localidades intermedias nos remiten los lugares de nacimiento de los que no eran oriundos de los caseríos y pueblos del Departamento Antofagasta.

En cuanto al presente, los viajes han mermado considerablemente $y$, como dijimos antes, no es necesario viajar para obtener lo que no se produce en la puna. Simplemente hay que esperar que vengan los camiones $y$, por dinero o por productos, adquirir lo que se desea.

De todas maneras y desde los pueblos menos comunicados se siguen organizando viajes a veces, bastante riesgosos, como es el que lleva hacia Fiambalá. En el caso que hemos considerado, creemos que estos viajes de intercambio siguen siendo redituables gracias a la disponibilidad de sal gratuita. En otros casos, residir cerca del camino vehicular se convierte en la ventaja de los que inician el viaje de intercambio. Pueden, por esta razón, acceder a mercaderías que venderán en los puestos y estancias alejados de tales caminos.

Como en otros países de América, castigados por los avatares de una economía monetaria incontrolable para la población, la persistencia del trueque -e incluso su reciente instalación como mecanismo de intercambio en zonas donde hasta hace poco 
no existía- permite un espacio de cierta seguridad para obtener al menos lo necesario para subsistir.

El hecho de ser un comercio que depende fuertemente de las relaciones personales amigos, parientes, conocidos- le añade un "valor agregado" que puede permitir enriquecer una caracterización social y cultural. Dicho con otras palabras el estudio de las relaciones parentales, de amistad y comerciales y sus redes a través de las unidades familiares y en los viajes, aportan datos indispensables para la descripción y análisis de la estructura social de un ámbito bastante extenso de América del Sur: el altiplano andino.

\section{Agradecimientos:}

A los pobladores de Antofagasta de la Sierra y de El Peñón.

\section{Bibliografía}

Brackenbush, Luis 1990. (1883) Por los caminos del Norte. Universidad Nacional de Jujuy. San Salvador de Jujuy.

Browman, David. (1994) "Información y manejo de riesgo de los fleteros de llamas en los Andes centro Sur" en Zooarqueología de camélidos, 1,1, pp.23-42.

Burchard, Roderick (1980). "Exogamia como estrategia de acceso a recursos interzonales: un caso en los Andes centrales del Perú" en Parentesco y matrimonio en los Andes. Mayer, E. y Bolton, R. (ed.), pp. 593-617.

Cipolletti, María Susana.(1984) "Llamas y mulas, trueque y venta: el testimonio de un arriero puneño" en Revista Andina. Centro de Estudios Rurales Andinos "Bartolomé de Las Casas", Cusco, Perú. Año 2, n².

Flores Ochoa, J. y Yemira D. Najar Vizcarra. (1980) "Un aspecto del parentesco de los Pastores de la puna alta" en Parentesco y matrimonio en los Andes. Mayer, E. y Bolton, 
R. ed., pp. 481-492, Pontificia Universidad Católica, del Perú.

Flores Ochoa, Jorge (1977). "Pastoreo, tejido e intercambio" en: Pastores de Puna, Lima, Instituto de Estudios Peruanos, pp. 133-154.

García, Silvia y Diana Rolandi (1999) "Viajes comerciales, intercambio y relaciones sociales en la población de Antofagasta de la Sierra, puna meridional argentina" en Propuestas para una antropología argentina, V, Bs. As.

Holmberg, Eduardo (1900) Viaje por la Gobernación de los Andes. Buenos Aires, Imprenta de "La Nación".

Inamura, Tetsuya (1986) "Relaciones estructurales entre pastores y agricultores de un distrito altoandino en el sur del Perú" en Etnografía e Historia del mundo andino. Shozo Masuda, (ed.) Universidad de Tokio.

Juvenal Casaverde, R. (1977) "El trueque en la economía pastoril" en Pastores de Puna, Lima, Instituto de Estudios Peruanos, pp. 171-192.

Reichert, Fritz (1907) Los yacimientos de boratos y otros productos minerales explotables del Territorio de Los Andes (Puna de Atacama.) Buenos Aires, Anales del Ministerio de Agricultura, Talleres de Publicaciones de la Oficina Meteorológica Argentina, t. II, $n^{\circ} 2$. 
Redes - Revista Hispana para el análisis de redes sociales. Volumen 2\#5

ANEXO: Mapas

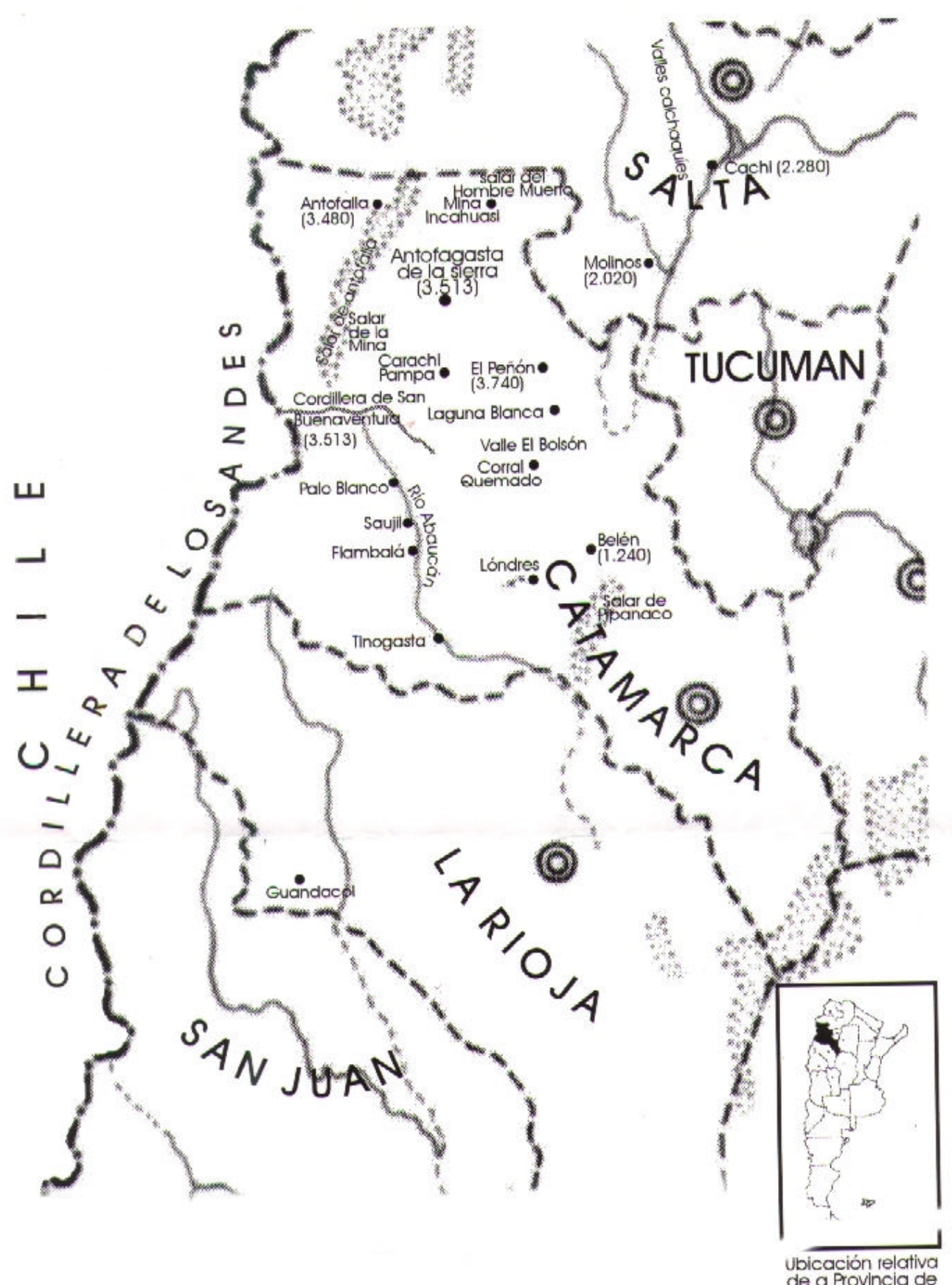

de a Provincia de

23 


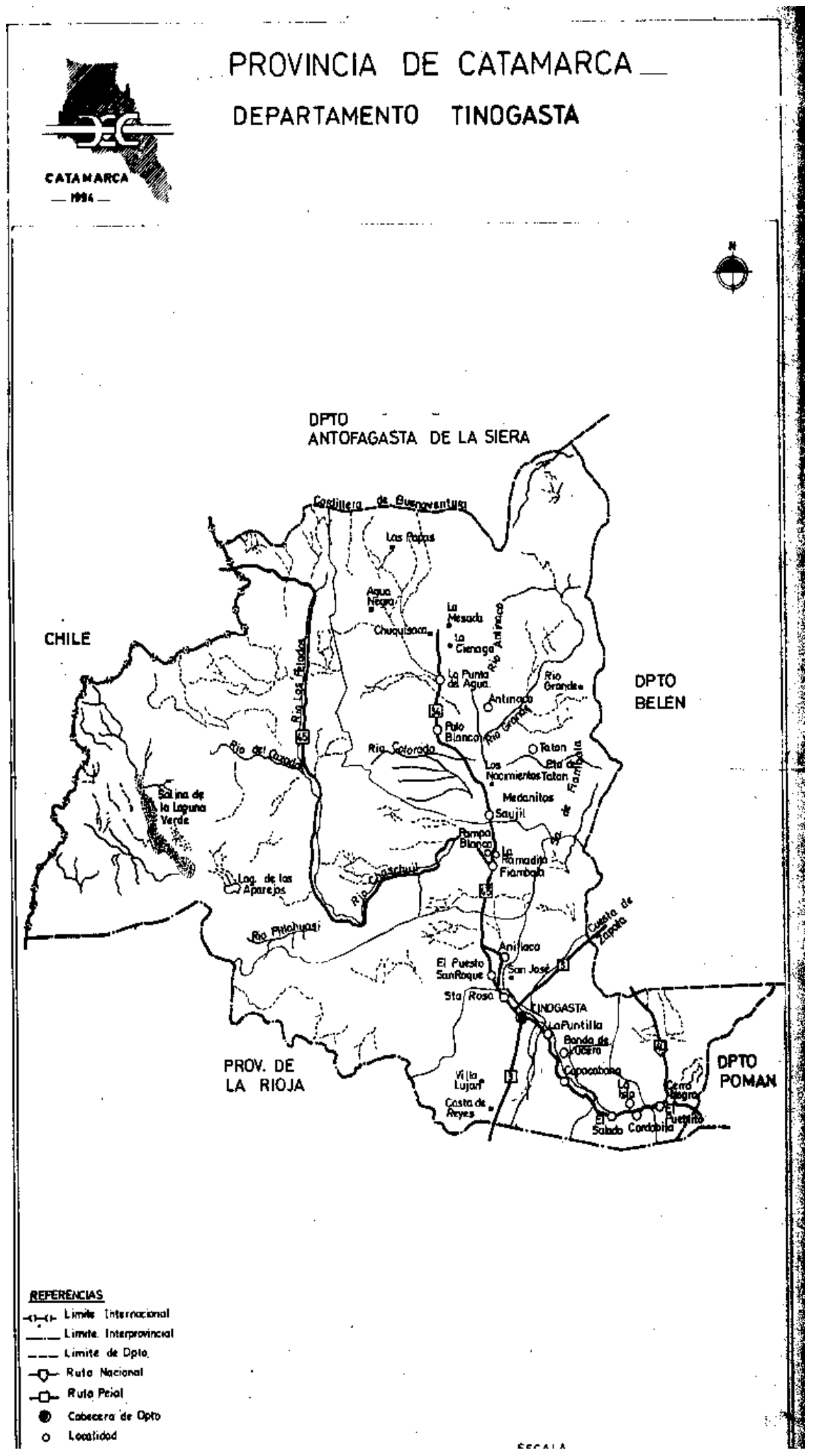

